Sharif University of Technology
Scientia Iranica
Transactions E: Industrial Engineering
http://scientiairanica.sharif.edu
IRAENTIA

\title{
Sustainable model of port-hinterland freight distribution network considering uncertainty: A case study of Iran
}

\author{
M. Mohammadpour Omran*, R. Ghousi, and A. Taherkhani Kadkhodaei \\ Department of Industrial Engineering, Iran University of Science and Technology, Tehran, P.O. Box 16846-13114, Iran.
}

Received 30 April 2020; received in revised form 21 January 2021; accepted 26 April 2021

\author{
KEYWORDS \\ Logistic; \\ Port; \\ Hinterland; \\ Inland terminals; \\ Transportation; \\ Freight; \\ Distribution; \\ Robust.
}

\begin{abstract}
According to the significant role of ports, port-hinterland distribution networks considering various parameters have received much attention in recent years. Considering intermodal transport and the possibility of constructing new inland terminals where transportation mode changes, this paper aims to investigate the subject of port-hinterland freight distribution network. To this end, considering the volume of exported freight being delivered as well as imported freight received, a multi-objective intermodal model was developed for Iran as our case study. In this model, it was assumed that in addition to the existing railway and road routes in the country, new railway and road routes could be constructed, as well. The first objective function involves minimizing the cost of transportation and the cost of constructing an inland terminal. The second objective function involves minimizing $\mathrm{CO}_{2}$ released during freight transport. A certain model for the problem was described first and then, uncertainty in the amount of import demand and export supply was considered. A robust modeling approach was employed. Therefore, data of the goods imported from or exported to Iran were collected and solved using the robust model in GAMS software; then, the results were analyzed and investigated.
\end{abstract}

(C) 2023 Sharif University of Technology. All rights reserved.

\section{Introduction}

In recent years, optimization of port-to-port connection has played a key factor in transportation chain from origin to destination and it is of paramount importance. Along with changes happening to the traditional forms of commodity exchange, various factors are essential to the design of a freight distribution network. Thus, re-

*. Corresponding author. Tel.: +982173225034

E-mail addresses: omran@iust.ac.ir(M. Mohammadpour

Omran); ghousi@iust.ac.ir (R. Ghousi);

ahmad.taherkhani@gmail.com (A. Taherkhani Kadkhodaei)

doi: $10.24200 /$ sci.2021.55884.4447 searchers try to involve them in their recent modeling. The concept of the port, which was considered in the past merely as a place to transport goods from sea to land or vice versa, has developed in recent years and has led to various generations of ports, each of which has more roles to play than the previous generation. In the meantime, the connection between two concepts of port and hinterland has made it impossible to separate port from hinterland in the design of a freight distribution network so that the hinterland connectivity can be expressed as the second most important factor in port competitiveness, followed by port costs [1]. On the other hand, with the development of intermodal transport in recent years, governments have tried to increase the role of rail transport in the design of transport 
infrastructure, because rail transport is proved to do less damage to the environment than road transport. In general, following the change to the role and concept of port, development of intermodal transportation as well as considering environmental protection at the same time resulted in a new perspective in the design of port-hinterland distribution network. Currently, in the transportation industry, environmental protection has become a vital concern in the field of sustainable development, which is considered to be an issue tied to the intermodal transportation industry; therefore, it is important to examine the connection between environment protection and sustainable development.

Intermodal transportation, rationalization of transportation chain, and reduction of energy consumption encourage a reasonable use of infrastructure. It, therefore, reduces environmental impact by using high maritime capacity and rail transportation. In addition, it benefits from the greater flexibility offered for road transport [2]. Moreover, the development of integrated intermodal transport networks, the establishment of interconnected networks of inland terminals, and the fast-increasing involvement of shipping industry actors in door-to-door services and operations placed a greater emphasis on the importance of hinterland transport connectivity in shaping port competitiveness [3]. Given the excessive growth of maritime transport and the connection between port and hinterland, if old structures receive no improvements whatsoever, transportation system is expected to explode as a cause of problems due to inefficiency. Therefore, changing current structures and paying special attention to environmental sustainability in new structures is a vital matter. Since train and barge are less likely to release $\mathrm{CO}_{2}$ than truck and road vehicles, it can be concluded that intermodal network is capable of offering more sustainable options [4]. In the meantime, since each of these goals may be in conflict with the managerial goals of each of these players, the way of managing the exchange between these modes is a big challenge for transportation and logistics planners, operators, and customers. In the models proposed for the port-hinterland freight distribution network in this paper, a strategic view of the mentioned concerns has received less attention [5].

In this study, based on existing gaps, a strategic and multi-objective model is presented, indicating the means to use rail and road transportation modes along with the rate of ports and inland terminals operation, which is determined based on the amount of import and export of supply and demand nodes. Terminals, also known as dry port, logistic park, or distribution center, are places for goods transportation, mode change, and allocation of added value on goods. Iran has been chosen as the case study of the current study, and the provinces are considered as the nodes of supply and demand or the origin and final destination of the goods. In this model, possibilities such as constructing new rail/road routes have been considered and the current network could be optimized and developed with the construction of new routes. The model determines which direction a freight should be sent directly from port to province and where an inland terminal shall be constructed to change the transportation mode. The first objective function of this model involves minimizing the cost of transportation (for both import and export) and the cost of constructing an inland terminal. The second objective involves minimizing $\mathrm{CO}_{2}$ released during freight transport. In this model, in order to deliver the imported goods into the country, the model first determines how many goods could be imported to each seaport and, then, decides how and by which transportation mode (rail or road) freights should be sent from seaports to provinces based on the demand of each node (individual provinces). Regarding the matter of export goods, the model, based on the export volume of each province and transportation mode (rail or road), decides how to collect the goods from each province and to send them to the target ports. In the process of transporting goods (import/export) from one province to another, if there was a need to change the transportation mode, an inland terminal shall be constructed.

Since a certain model with approximation may lead to erroneous decisions, one of the most important challenges in supply chain management is the uncertainty of demand and supply (more closely approximated by forecasts), which is a prominent factor in precise decision-making. Demand and supply, in actual design problems of port-hinterland freight distribution network, are very dynamic and should be described as random variables. According to the literature, few authors have addressed the issue of uncertainty. A common assumption in most studies of supply chain management given random demand (supply) is that the probability distribution of demand (supply) is well known; yet, its availability is rare or very difficult. Obviously, if there is no complete information about the probability distribution of demand (supply), solving the problem of "port-hinterland distribution network" requires attention to random demand (supply) in a flexible way. Using such parameters, robust optimization has proven to be a powerful method for random problems with the distribution of unknown probabilities. This method guarantees a feasible answer by finding a minimax solution, regardless of certain values of unknown variables. Based on the information obtained in the current study and the literature, we found that the design of the port-hinterland connection network using robust optimization has received insufficient attention. As a result, in this paper, considering the uncertainty in the extent of demand and supply in each province, 
a robust optimization approach is used to apply the uncertainty conditions to the model. The innovations realized in this article are explained in brief below:

i. A new model in the design of a port-hinterland distribution network, considering intermodal transportation network, the possibility of construction of an inland terminal when mode change happens, and the possibility of constructing new transport routes, has been proposed;

ii. Based on the literature review, this is one of the first studies on the design of a port-hinterland distribution system using robustness for modeling;

iii. Since robust optimization cannot be applied to equal constraints (e.g., equality is not possible in case of uncertainty), a robust optimization method is presented for equal constraints including the parameters related to demand and supply;

iv. Moreover, this problem has been solved in a practical way for provinces in Iran as our case study.

This study benefits from the actual data provided by the Center of Statistics and Ministry of Roads and Urban Development in Iran.

\section{Literature review}

Two types of qualitative and quantitative studies have been done on the subject of this research. In fact, this article focuses on qualitative issues, including how to manage infrastructure, how to deal with matters related to goods distribution between seaport and hinterland, and how to manage inland terminals. Most important qualitative studies conducted over the subject of policy-making in a port-hinterland system include Dooms et al. [6] in 2015; Veenstra et al. [7] in 2012; and Van den Berg \& De Langen [8] in 2015. Monios [9] focused on how to develop inland terminals as well as their role in strategic access from seaports to hinterland; this study was done on Spanish ports. Yulia Panova and Hilmola [10] pointed out the economic importance of dry ports/inland terminals and distribution centers in economic development of countries; they examined the possible means of investment to achieve the intended development in Russia. Using the UK as a case study, Woodburn [11] investigated the effect of increase in rail mode share. Results show the operational efficiency improvements and reduction in the negative externalities per unit of transport activity in the hinterland.

In 2013, Roso [12] investigated intermodal transport between seaport and dry port as a solution to reduce inland terminal congestion as well as better access to the port and inland terminals. This study was done based on the investigation of short rail travels. The aim of this qualitative study is to analyze the effects of the development of dry ports on the sustainability of intermodal transport based on rail transport. Some studies have been conducted on the importance of dry ports. Dry ports play an important role in designing the structure of the port network. To develop transport plans at a macro level, government agencies should carefully consider the characteristics of seaports and dry ports, the direction of development, and the level of activity of the dry ports [13]. The dry port concept has gained significant attention among researchers all around the world, mainly due to its potential to improve hinterland intermodal transportation, generate economic benefits, and reduce environmental impacts [14].

Although there already are various mathematical models proposing port-hinterland transportation network development, few have paid direct attention to the challenges addressed in this article. During the research done in this paper, few models were employed to address this subject strategically.

So far, no model has considered transport infrastructure development, including routes and inland terminals. In fact, no study has examined the transport infrastructure required for an optimal network situation as well as its costs imposed from the establishment of a port-hinterland network. Moreover, no study was found to consider environmental issues including $\mathrm{CO}_{2}$ emissions reduction.

In 2016, Halim et al. [5] conducted the most significant strategic research in this field and presented a strategic model for port-hinterland freight distribution as a result. In their model, they used a multi-objective optimization combination to estimate the location as well as the network of distribution centers selected according to the different levels of service. The case study of this article was the Europe continent. The measures included port-hinterland transport cost, porthinterland transport time, and distribution centerhinterland transport time.

Many other models have been used to study this subject at the tactical level. In 2016, Lam and $\mathrm{Gu}$ [15] attempted to minimize time, cost, and the amount of gases emitted by vehicles in their article, the first two of which were directly linked to the objective functions of a bi-objective problem and the third was taken as the constraint of the problem. In this model, the containers could be sent from foreign ports to domestic seaports. After emptying containers in domestic seaports, custom duties should be carried out before they would be sent to the final customers in domestic cities through the domestic transport network. Three types of vehicles including rail, barge, and truck were considered as transportation modes in this model. Railway and barge are the available modes prior to the step of truck delivery, and it is preferred to use these two at first; otherwise, a truck must be used for the entire route from ports to the end customer. 
In 2008, by combining the transport system like hub-and-spoke with the integrated transport system between ports and hinterlands, Wang [16] presented an optimal two-level nonlinear model for the logistics system. In 2010, Mingjun and Maoying [17] proposed a two-tier planning model, in which the upper objective was the total cost of transportation in the regional port group, while the lower objective was the economic profit of a single firm. This paper considered hinterland dynamics of each port in the logistics transportation system. In 2010, Iannone and Thore [18] introduced an intermodal model to develop a multi-faceted freight transfer problem in Italy. The model presented in this study minimizes the total logistical costs through the port-hinterland network, which is limited to balancing the terms in the nodes and the constraints in railways capacities. Logistics costs include transportation costs (by road and rail), customs and terminal operating costs, and in-transit holding costs. In 2009, Kim et al. [19] investigated the relationship between transportation costs and $\mathrm{CO}_{2}$ emissions in a network. In the case of changing different factors, the exchange between factors changes the direction of transportation. The freight network in this research presents a different combination of transportation modes, in which, by changing the mode and route, this system should achieve an acceptable amount of $\mathrm{CO}_{2}$ emission, along with reasonable time and place. In this paper, a multiobjective optimization technique was employed.

In 2008, using a location-allocation model, Rahimi et al. [20] examined the potential to integrate domestic ports in an intermodal regional freight transportation system; they selected southern California as a case study. In this paper, by analyzing the movement of trucks, potential locations for domestic ports were identified first; then, six domestic ports were selected using the model. In 2013, Feng et al. [21] proposed a location-allocation model to optimize the seaport-domestic port network and then, solved the model through a genetic and grade algorithm. This study was conducted in Taiwan and various aspects of transportation were not considered in this article.

In 2013, Lättilä et al. [22] investigated the wideranging uses of rail in transportation to reduce $\mathrm{CO}_{2}$ emission. Railway connects distribution centers (domestic ports) to seaports. In this paper, two different configurations were compared; in the first one, the shippers are directly connected to the seaport, while in the second one, they use dry ports. The system is evaluated using event-discrete simulation. In this system, $\mathrm{CO}_{2}$ emission levels along with transportation costs in different configurations have been investigated. In a study conducted in Finland, the effect of constructing dry ports on reducing transportation costs was investigated and then, it was compared with that in Sweden. The outcome of the integer programming model employed in this study indicates that the existence of dry ports reduces costs and attenuates the effect of released harmful gases [23]. In 2018, Wang et al. [24] developed a mathematical model for optimizing the dry port location and investigating the operations in a dry port. In 2015, Chang et al. [25] presented a template for the optimal and reasonable design of a dry port, which had been designed for a Chinese port named Dalian. In 2015, Zhang et al. [26] proposed a model for optimizing freight transportation that simultaneously considers intermodal structure, hub-centric network, and various design goals of the players. The model was validated using real data from Netherland's hinterland container shipping.

In 2018, Aregall et al. [27] reviewed the importance of ports and hinterland in reducing greenhouse gases. In this regard, studying several ports in the globe, they intended to identify ports that define measures to reduce gas emissions, hence determining to what extent they have been successful. The research results have shown that congestion in ports plays a key role in increasing greenhouse gas emissions associated with the ports, and the public ownership of ports highlights this key role. In 2018, $\mathrm{Hu}$ et al. [28] investigated mathematical models for the planning of container movements in a port area, integrating the inter-terminal transport of containers with the rail freight formation and transport process. An integer linear programming model was applied to formulate the container transport across operations at container terminals, the network interconnecting them, railway yards, and the railway networks towards the hinterland. A tabu search algorithm was proposed to solve the problem.

In 2019, Santos and Soares [29] presented a model for defining and optimizing the overall cost of port hinterland; these costs included shipping costs, inland port costs, and transit costs. In addition, in this research, transportation was conducted by using roads and railways. This study was conducted as a case study in the western Iberian Peninsula. The results allowed identifying the main hinterland of different terminals based on the overall costs and the analysis of the effects of intermodal terminals on promoting the regionalization process.

Resat and Turkay [30] developed a model that included different objective functions including total transportation cost, travel time, and $\mathrm{CO}_{2}$ emissions while optimizing the proposed network structure. Traffic congestion, time-dependent vehicle speeds, and vehicle filling ratios were considered and computational results in different illustrative cases were presented with real data from the Marmara Region of Turkey. The defined non-linear model was converted into a linear form and solved using a customized implementation of the $\varepsilon$-constraint method. 
In 2019, Liu et al. [31] presented a model based on the system dynamics to assess the emissions in the hinterland. This model was implemented in China in order to evaluate environmental policies on emissions. Therefore, by examining different policies in the form of scenarios and displaying the hinterland transportation process, the model clearly identifies the amount of emission. The model successfully determined the effective scenario to minimize emission, including the regulation of rigid truck weight and construction of a grade-I railway. In 2020, Van Nguyen et al. [32] proposed a two-stage approach to combining data mining with complex network theory to optimize the locations and service areas of dry ports in a largescale inland transportation system. First, candidate locations of dry ports were weighted based on their eigenvector centrality in the complex network of association rules mined from a large amount of international transaction data. Second, dry port locations and their service areas were optimized using the gravitybased community structure. Recently, Jiang et al. [33] did not incorporate ports directly in the modeling process and took demand uncertainty into account for the development of a multimodal logistics network. According to the determined logistics demand pattern, this multi-stakeholder decision-making problem was first formulated as a bi-level programming model. This model was followed by its equivalent Mathematical Programming with Equilibrium Constraints (MPEC) to depict the leader-follower behaviors. In order to capture the risk aversion level of the logistics authority in an uncertain demand environment, an improved adjustable robust optimization method is proposed. This method includes an individual control parameter and provides an exact expression of maximum satisfaction probability.

Despite the studies done so far, clearly, the models that can choose how to develop intermodal transport infrastructure and the required terminals considering current network status simultaneously have received less attention. In addition, no model provides a robust optimization approach to solving a problem with uncertainty in supply and demand. Therefore, this study adopts a new approach.

\section{Problem modeling}

In this model, $N$ represents a set of seaports ( $p \in$ $\{1,2, \cdots, P\})$ in addition to a set of provinces $(i \in$ $\{1,2, \cdots, I\})$ defined as $N=P \cup I$. Transport mode between nodes of $N$ set is represented by a finite set $(v \in\{1,2, \cdots, V\})$, such that between two nodes of $N$ set, there can be one or several possible transport modes. In this research, on the one hand, goods imported into the country are first imported to several seaports and, then, goods can be sent from the ports to the provinces one after another. On the other hand, the goods supposed to be exported from the country can also be collected from the provinces in the same manner and then, to be sent to the ports. Moreover, should there is a need to change the transport mode in provinces that are either in the way of imported or exported goods transportation, an inland terminal must be established in that province. This model has two objective functions: the first seeks to minimize the cost of establishing inland terminals and new routes as well as the cost of goods transportation. This is while the second objective function seeks to minimize the amount of $\mathrm{CO}_{2}$ emission caused by goods transportation.

The assumptions of mathematical modeling in the problem are given as follows:

- The capacity of inland terminals and seaports is assumed unlimited;

- The number of transport vehicles is assumed unlimited;

- The cost of establishing an inland terminal is assumed to be averaged.

Sets:

$m, n \quad$ Total set of nodes (including set of seaports and set of provinces)

$p \quad$ Set of seaports

$i, j \quad$ Customer points (Provinces)

$v \quad$ Transfer mode set

\section{Parameters}

$d i s_{n m v} \quad$ Distance between nodes $n$ and $m$ in the transport mode number $v$

$f_{n m v} \quad$ If the transport mode number $v$ exists between nodes $n$ and $m$, it is 1 ; otherwise, 0

$e_{i} \quad$ Cost of establishing an inland terminal number $i$

$d_{i} \quad$ Demand quantity of province number $i$

$s_{i} \quad$ Supply quantity of province number $i$

$\mathrm{co}_{v} \quad$ Amount of $\mathrm{CO}_{2}$ produced by transport mode number $v(\mathrm{~g} / \mathrm{ton} / \mathrm{km})$

$c_{v} \quad$ Amount of transfer cost by transport mode number $v$ (USD/ton $/ \mathrm{km}$ )

$E c_{v} \quad$ Cost of establishing a one-way transport route with transport mode number $v(\mathrm{USD} / \mathrm{km})$

$f_{n m v}^{\prime} \quad$ If there is a capability to establish a new inland terminal between nodes $n$ and $m, 1$; otherwise, 0

\section{Variables}

$o_{p} \quad$ Amount of goods imported to the seaport number $p$ 
$w_{p} \quad$ Amount of goods exported from the seaport number $p$

$x_{n m v} \quad$ Amount of imported goods transferred from node $n$ to node $m$ in transport mode $v$

$u_{n m v} \quad$ Amount of exported goods transferred from node $n$ to node $m$ in transport mode $v$

$d_{i v}^{\prime} \quad$ Amount of demand by province number $i$ supplied by transport mode number $v$

$s_{i v}^{\prime} \quad$ Amount of supply by province number $i$ transferred by transport mode number $v$

$y_{n m v} \quad$ If the imported goods can be supplied from node $n$ to node $m$ with transport mode number $v$ (available path), it is 1 ; otherwise, 0

$v_{n m v} \quad$ If the exported goods can be transferred from node $n$ to node $m$ with transport mode number $v$ (available path), it is 1 ; otherwise, 0

$z_{i} \quad$ If the transport mode in the province number $i$ was changed, or if an inland terminal was established in that city, 1 ; otherwise, 0

$z_{i v}^{1} \quad$ An additional variable that if the quantity of goods imported into the province number $i$ minus that of goods imported out of it receives a positive value in the transport mode number $v$, it is 1 ; otherwise, 0

$z_{i v}^{2} \quad$ An additional variable that if the value of goods imported out of province $i$ minus that of imported into it in transport mode number $v$ was positive, it is 1 ; otherwise, 0

$z_{i v}^{3} \quad$ An additional variable that if the amount of exported goods out of province $i$ minus that of imported ones into province $i$ in positive transport mode number $v$ receives a positive value, it is 1 ; otherwise, 0

$z_{i v}^{4} \quad$ An additional variable that if the value of the exported goods to the province $i$ minus that of the exported goods from the province $i$ receives a positive value in transport mode number $v$, it is 1 ; otherwise, 0

$r_{n m v}^{1} \quad$ If transportation could be done from node $n$ to node $m$ in the transport mode $v$ with the construction of a new route in order to supply imported goods, it is 1 ; otherwise, 0 $r_{n m v}^{2} \quad$ If transportation could be done from node $n$ to node $m$ in the transport mode $v$ with the construction of a new route in order to transfer exported goods, 1 ; otherwise, 0

$r_{n m v} \quad$ Transportation could be done from node $n$ to node $m$ in the transport mode $v$ with the construction of a new route (one-way route), 1 ; otherwise, 0

\subsection{Deterministic model}

Here, the deterministic model of the problem is described first based on which the non-deterministic model is presented below:

$$
\begin{aligned}
\min z_{1}= & \sum_{l} e_{i} z_{i}+\sum_{v} \sum_{m} \sum_{n} c_{v} d i s_{n m v}\left(x_{n m v}+u_{n m v}\right) \\
& +\sum_{v} \sum_{m} \sum_{n} E c_{v} d i s_{n m v}\left(r_{n m v}\right) \\
\min z_{2}= & \sum_{v} \sum_{m} \sum_{n} c o_{v} d i s_{n m v}\left(x_{n m v}+u_{n m v}\right)
\end{aligned}
$$

s.t.

$o_{p}=\sum_{v} \sum_{i} x_{p i v}$

$\forall p$,

$\sum_{v} \sum_{n, n \neq i} x_{n i v}=\sum_{v} \sum_{j, j \neq i} x_{i j v}+d_{i}$

$d_{i}=\sum_{v} d_{i v}^{\prime}$

$\forall i$

$\sum_{n, n \neq i} x_{n i v}-\left(\sum_{n, n \neq i} x_{i n v}+d_{i v}^{\prime}\right) \leq \mathrm{M} z_{i v}^{1} \quad \forall i, v$

$\left(\sum_{n, n \neq i} x_{i n v}+d_{i v}^{\prime}\right)-\sum_{n, n \neq i} x_{n i v} \leq M z_{i v}^{2} \quad \forall i, v$

$x_{n m v} \leq M\left(y_{n m v}+r_{n m v}^{1}\right)$

$\forall n, m, v,(8)$

$y_{n m v} \leq f_{n m v}$

$\forall n, m, v,(9)$

$r_{n m v}^{1} \leqslant f_{n m v}^{\prime}$

$\forall n, m, v$,

$\sum_{v}\left(y_{n m v}+y_{m n v}+r_{n m v}^{1}+r_{m n v}^{1}\right) \leq 1$

$w_{p}=\sum_{v} \sum_{i} u_{i p v}$

$\forall p$,

$\sum_{v} \sum_{j, j \neq i} u_{j i v}+s_{i}=\sum_{v} \sum_{n, n \neq i} u_{i n v} \quad \forall i$

$s_{i}=\sum_{v} s_{i v}^{\prime}$

$\forall i$ 


$$
\begin{aligned}
& \left(\sum_{n, n \neq i} u_{n i v}+s_{i v}^{\prime}\right)-\sum_{n, n \neq i} u_{i n v} \leq M z_{i v}^{3} \quad \forall i, v \\
& \sum_{n, n \neq i} u_{i n v}-\left(\sum_{n, n \neq i} u_{n i v}+s_{i v}^{\prime}\right) \leq M z_{i v}^{4} \quad \forall i, v \\
& u_{n m v} \leq M\left(v_{n m v}+r_{n m v}^{2}\right) \quad \forall n, m, v, \\
& v_{n m v} \leq f_{n m v} \\
& \forall n, m, v, \quad(18 \\
& r_{n m v}^{2} \leq f_{n m v}^{\prime} \\
& \forall n, m, v, \\
& \sum_{v}\left(v_{n m v}+v_{m n v}+r_{n m v}^{2}+r_{m n v}^{2}\right) \leq 1 \\
& r_{n m v} \geq r_{n m v}^{1} \\
& \forall n, m, v, \\
& r_{n m v} \geq r_{n m v}^{2} \\
& \forall n, m, v, \\
& \sum_{v} z_{i v}^{1}+z_{i v}^{2}+z_{i v}^{3}+z_{i v}^{4} \leq M z_{i} \\
& o_{p}, x_{n m v}, d_{i v}^{\prime}, w_{p}, u_{n m v}, s_{i v}^{\prime} \geq 0 \quad \forall p, n, m, v, \\
& z_{i v}^{1}, z_{i v}^{2}, y_{n m v}, z_{i v}^{3}, z_{i v}^{4}, v_{n m v}, z_{i}, r_{n m v}, r_{m n v}^{1} \\
& r_{m n v}^{2} \in\{0,1\} \\
& \forall i, n, m, v \text {. }
\end{aligned}
$$

Eq. (1) represents the objective of function number 1 , thus minimizing the cost of establishing a terminal as well as the cost of transport between the nodes. Eq. (2) represents the objective of function number 2, which involves minimizing the amount of $\mathrm{CO}_{2}$ released during transport between nodes. Constraint Eq. (3) ensures that the amount of imported goods to each seaport is equal to the quantity of goods imported out of that. Eq. (4) examines the balance of import flows in each province, ensuring that the inflows of goods imported into each city are equal to the outflows of imports of that. Constraint Eq. (5) ensures that the total demand of each province is equal to the sum of the quantity of demand in each transportation mode. Constraint Eqs. (6) and (7) indicate whether the transportation mode for delivering the imported goods at node $i$ has changed. Constraint Eq. (8) ensures that the quantity of imported goods between two specific provinces can be transferred with one transportation mode, either with an existing transportation mode or the one that would be constructed. Constraint Eq. (9) indicates that if there already is a transport mode for transferring the imported goods, there will be no need to construct a new route, while Constraint Eq. (10) indicates that if there is no available transport mode, a new route will be constructed. Constraint
Eq. (11) ensures that between two specific nodes for transferring imported goods, only one mode would be selected. Constraint Eq. (12) ensures that the amount of exported goods entering into each seaport is equal to the quantity of exported goods discharged from that. Eq. (13) examines the balance of export flows in each province; more precisely, it ensures that the export inflows of each city are equal to the export outflows of the same city. Eq. (14) ensures that the total supply of each province is equal to the sum of quantity supplied by each transport mode. Eqs. (15) and (16) indicate whether the transportation mode for collecting export commodities at the $i$ th node has changed. Constraint Eq. (17) ensures that the quantity of exported goods between two specific provinces can be transferred in one mode; either the existing or a suitable mode would be constructed. Eq. (18) indicates that if there already is a transport mode for transferring the exported goods, there will be no need to construct a new one, while Eq. (19) indicates that if there is no available transport mode for transferring the exported goods, a new transport mode can be constructed on the same route. Constraint Eq. (20) ensures that between two nodes for the exported goods, only one transport route would be selected. Eqs. (21) and (22) indicate that constructing a new transport mode between nodes $n$ and $m$ is only acceptable if it is to be used as a transport mode for either imported or exported goods, or even both. Constraint Eq. (23) indicates that an inland terminal can be established in each province when the transportation mode is modified. Finally, Eqs. (24) and (25) specify the type of decision variables.

\subsection{Uncertainty}

Uncertainty can be defined as the difference between the amount of information required to proceed with a research piece and the amount of information that is actually available. Uncertainty here refers to the uncertainty in parameters. Therefore, although certain optimization problems are usually formulated and solved when the data are certain, most data suffer from uncertainty in everyday real-world problems. Uncertainty can affect the optimization and justification of problems. In real-world problems, changing one of the data may violate a great number of constraints, making the results non-optimal or even impossible. So far, three main approaches namely optimization, including stochastic, fuzzy, and robust optimization have been developed to address uncertainty in optimization issues. Stochastic optimization models were first developed by Dantzig and Bill in 1995. These models provide a possible perspective to replace certainty concerning unknown coefficients and parameters. Many uncertainty models take statistical distributions into account for uncertain data. Thus, these models can be used when either the uncertainty 
distribution of the parameters is known and clear, or a certain distribution of parameters can be adjusted. Fuzzy logic was first invented in 1960 by Dr. Lotfizadeh, a Professor of Computer Science at the University of California, Berkeley. Fuzzy logic believes that ambiguity is in the nature of science. Unlike others believing that approximations need to be more precise to increase productivity, Lotfizadeh maintains that models should strive to model ambiguity as part of the system. Fuzzy logic and its use to model uncertainty largely depends on the available expert and the nature of the uncertainty parameter.

In the field of robust optimization, Soyster [34] developed a pessimistic robust approach in order to deal with inaccurate linear programming problems. A robust decision is a decision that resists the uncertainty of the environment and the resulting performance fluctuates minimally. The answer to an optimization problem can be called a robust answer if it enjoys feasibility and optimality robustness. Feasibility robustness means that the answer must remain feasible for all (most) possible uncertain parameters. Robust optimization means that the value of the objective function for a robust answer must be close to its optimal value for all (most) possible cases of uncertainty parameters; or, in other words, it must have the least deviation from its optimal value. Therefore, in order to model uncertainty in robust models, there is no need to know the distribution of uncertainty nor the necessity of an available expert. It is merely enough to know the constraints of the uncertain parameter. These models are easier to use for modeling uncertainty than stochastic and fuzzy models.

\subsubsection{Convex robust models}

In an optimization problem, suppose that $J_{i}$ is defined as a set of parameters of the technological matrix $A$ that are uncertain in the $i$ th row. Any data with uncertainty $a_{i, j}, j \in J$ is defined as an independent and symmetric random variable $\tilde{a}_{i j}$ that belongs to the range $\left[a_{i j}-\hat{a}_{i j}, a_{i j}+\hat{a}_{i j}\right]$ with the central value of $a_{i j}$. To model any uncertain variable, deviation from the nominal value is defined as follows:

$$
z_{i j}=\left(\hat{a}_{i j}-a_{i j}\right) / \hat{a}_{i j},
$$

which varies in the interval $[-1,1]$.

The robust model provided by Soyster is one of the first robust models; it is a linear model in which all uncertainty parameters are at their worst values.

$$
\begin{array}{ll}
\min \sum_{j} c_{j} x_{j}, & \\
\sum_{j} a_{i j} x_{j}+\sum_{j \in J_{i}} \hat{a}_{i j} x_{j} \leq b_{i} & \forall i, \\
x_{j} \geq 0 & \forall j .
\end{array}
$$

This model is very conservative and pessimistic. The value of the objective function obtained from this model is far from the amount of the nominal objective function. According to Ben-Tal and Nemirovski [35], the following robust approach was presented based on balancing stability and performance of the model:

$$
\begin{aligned}
& \min _{j} c_{j} x_{j}, \\
& \sum_{j} a_{i j} x_{j}+\gamma\left(\sum_{j \in J_{i}} \hat{a}_{i j} x_{j}+\pi_{i} \sqrt{\sum_{j \in J_{i}} \hat{a}_{i j} x_{j}^{2}}\right) \leq b_{i} \\
& \quad \forall i, \\
& x_{j} \geq 0 \quad \forall j,
\end{aligned}
$$

In this optimization problem, $\gamma$ is the parameter controlling the percentage of model variability. The authors of the paper proved that considering uncertainty space $U$, the probability of constraint $i$ being violated at the maximum is equal to $\exp \left(-\frac{\pi_{i}^{2}}{2}\right)$. The conservative level of this model is less than that of the Soyster model; moreover, the objective function value of robust optimization is lower than that of the certain model. However, this model is subject to computational complexity due to its nonlinearity feature. In order to counter the over-conservatism of the first model and the complexities of the second nonlinear model, Bertsimas and Sim [36] provided a linear model with a parameter to control the level of protection.

The current study argues that it is very unlikely for all uncertainty parameters to be at their worst at the same time. The maximum number of parameters that may deviate from their nominal value in each row in this model is equal to $\left[\Gamma_{i}\right]$. Considering $\Gamma_{i}$ or the "uncertainty" budget in the model, the "protection level" of any constraint is defined:

$$
\sum_{j \in J_{i}}\left|z_{i j}\right| \leq \Gamma_{i} \quad \forall i .
$$

The parameter $\Gamma_{i}$ belongs to the interval $\left[0,\left|J_{i}\right|\right]$. If $\Gamma_{i}=0$, the robust model is converted into a certain model and if $\Gamma_{i}=\left|J_{i}\right|$, this model will be converted into the pessimistic Soyster model. $\Gamma_{i}$ does not have to be integer; thus, the number of $\Gamma_{i}$ uncertainty parameters is in their worst condition, and one $\left(a_{i t}\right)$ parameter changes by $\left(\Gamma_{i}-\left\lfloor\Gamma_{i}\right\rfloor\right) \hat{a}_{i t}$ amount. Therefore, accordingly, it can be said that $\Gamma_{i}$ is a parameter that balances robustness and conservatism levels of the model according to decision-maker and practical requirements and makes the robust model realistic.

The model provided by Bertsimas and Sim is as follows: 


$$
\begin{array}{ll}
\min \sum_{j} c_{j} x_{j}, & \\
\sum_{j} a_{i j} x_{j}+\lambda_{i} \Gamma_{i}+\sum_{j \in J_{i}} \mu_{i j} \leq b_{i} & \forall i, \\
\lambda_{i}+\mu_{i j} \geq \hat{a}_{i j} x_{j} & \forall j \in J_{i}, \\
\mu_{i j} \geq 0 & \forall j \in J_{i}, \\
x_{j} \geq 0 & \forall j, \\
\lambda_{i} \geq 0 & \forall i .
\end{array}
$$

In the above optimization problem, $\mu_{i j}$ and $\lambda_{i}$ are dual auxiliary variables. Now, if the parameters on the right had uncertainty, we would have:

$$
\begin{array}{ll}
\min \sum_{j} c_{j} x_{j}, & \\
\sum_{j} a_{i j} x_{j} \leq \tilde{b}_{i} & \forall i, \\
x_{j} \geq 0 & \forall j .
\end{array}
$$

Therefore, $\tilde{b} \in\left[b_{j}-\hat{b}_{j}, b_{j}+\hat{b}_{j}\right]$ as a result of the Bertsimas and Sim model is given as follows:

$$
\begin{array}{ll}
\min \sum_{j} c_{j} x_{j}, & \\
\sum_{j} a_{i j} x_{j}+\theta_{i}+\tau_{i} \Gamma_{i} \leq b_{i} & \forall i, \\
\theta_{i}+\tau_{i} \geq \hat{b}_{i} & \forall i, \\
\tau_{i}, \theta_{i}, x_{j} \geq 0 . &
\end{array}
$$

\subsubsection{Robust problem modeling}

In this research, the amount of demand and supply of each province is uncertain. As a result, members $\tilde{d}_{\iota}$ and $\tilde{s}_{\iota}$ are defined as $\left[d_{i}-\hat{d}_{\iota}, d_{i}+\hat{d}_{\iota}\right]$ and $\left[s_{i}-\hat{s}_{\iota}, s_{i}+\right.$ $\left.\hat{s}_{l}\right]$, respectively, and for robust problem modeling, the Bertsimas and Sim method has been used since robust modeling does not work accurately for equal constraints (being impossible to establish equality in case of uncertainty). Therefore based on the robust approach provided by Bretsimas and Thiele [37] for inventory management and model presented by Hemmati Golsefidi and Akbari Jokar [38], the following method is presented, which is in fact a modeling approach for equality constraints including supply and demand parameters.

Constraint Eq. (4) of the certain model is equal to:

$$
\sum_{v} \sum_{n, n \neq i} x_{n i v}=\sum_{v} \sum_{j, j \neq i} x_{i j v}+\tilde{d}_{l} \quad \forall i
$$

In order to convert this equal constraint into an unequal one, the variable $d v_{i}^{1}$ was defined such that the amount of penalty for deviating from the above constraint equation could be calculated. The parameters $d v c_{i}^{1}$ and $d v c_{i}^{2}$ were defined as the values of penalty for each unit of deviation from equality, respectively, in cases when the demand of the provinces would be both higher and lower than the nominal value. Therefore, the above constraint equation should be rewritten as follows:

$$
\begin{aligned}
& \left(\sum_{v} \sum_{n, n \neq i} x_{n i v}-\left(\sum_{v} \sum_{j, j \neq i} x_{i j v}+\tilde{d}_{l}\right)\right) d v c_{i}^{1} \leq d v_{i}^{1} \\
& \forall i, \\
& \left(\left(\sum_{v} \sum_{j, j \neq i} x_{i j v}+\tilde{d}_{l}\right)-\sum_{v} \sum_{n, n \neq i} x_{n i v}\right) d v c_{i}^{2} \leq d v_{i}^{1} \\
& \forall i .
\end{aligned}
$$

Now, according to the Bertsimas-Sim method, it can be said that:

$$
\begin{gathered}
\left(\sum_{v} \sum_{n, n \neq i} x_{n i v}-\left(\sum_{v} \sum_{j, j \neq i} x_{i j v}+d_{i}\right)+\theta_{i}^{1}\right. \\
\left.+\tau_{i}^{1} \Gamma_{i}^{1}\right) d v c_{i}^{1} \leq d v_{i}^{1} \quad \forall i, \quad \Gamma_{i}^{1} \leq|1|, \\
\left(\left(\sum_{v} \sum_{j, j \neq i} x_{i j v}+d_{i}\right)-\sum_{v} \sum_{n, n \neq i} x_{n i v}+\theta_{i}^{1}\right. \\
\left.+\tau_{i}^{1} \Gamma_{i}^{1}\right) d v c_{i}^{2} \leq d v_{i}^{1} \quad \forall i, \quad \Gamma_{i}^{1} \leq|1|, \\
\theta_{i}^{1}+\tau_{i}^{1} \geq \hat{d}_{i} \\
\quad \forall i .
\end{gathered}
$$

Thus, $\Gamma_{i}^{1}$ is a parameter that determines the uncertainty budget set by the model decision-maker, and the variables $\tau_{i}^{1}$ and $\theta_{i}^{1}$ are the auxiliary variables used in the Bertsimas-Sim model. Parameters $d_{i}$ and $\hat{d}_{i}$ represent the demand nominal value and the value of deviation from demand nominal value, respectively.

Constraint Eq. (5) of the certain model is equal to:

$$
\tilde{d}_{l}=\sum_{v} d_{i v}^{\prime} \quad \forall i .
$$

Similar to Constraint Eq. (4), in order to convert this 
equal constraint into an unequal one, the variable $d v_{i}^{2}$ was defined in such a way that the amount of penalty for deviating from the above constraint equation could be calculated. Parameters $d v c_{i}^{3}$ and $d v c_{i}^{4}$ were also defined as the penalty values for each unit of deviation from equality, respectively, in cases when the demand of the provinces would be greater than the nominal value and when less than the nominal value.

Therefore, the above constraint equation should be rewritten as follows:

$$
\begin{aligned}
& \left(\sum_{v} d_{i v}^{\prime}-\tilde{d}_{l}\right) d v c_{i}^{3} \leq d v_{i}^{3} \quad \forall i, \\
& \left(\tilde{d}_{l}-\sum_{v} d_{i v}^{\prime}\right) d v c_{i}^{4} \leq d v_{i}^{4} \quad \forall i .
\end{aligned}
$$

Now, according to the Bertsimas-Sim method, it can be said:

$$
\begin{aligned}
& \left(\sum_{v} d_{i v}^{\prime}-d_{i}+\theta_{i}^{2}+\tau_{i}^{2} \Gamma_{i}^{2}\right) d v c_{i}^{3} \leq d v_{i}^{2} \\
& \forall i, \quad \Gamma_{i}^{2} \leq|1|, \\
& \left(d_{i}-\sum_{v} d_{i v}^{\prime}+\theta_{i}^{2}+\tau_{i}^{2} \Gamma_{i}^{2}\right) d v c_{i}^{4} \leq d v_{i}^{2} \\
& \forall i, \quad \Gamma_{i}^{2} \leq|1|, \\
& \theta_{i}^{2}+\tau_{i}^{2} \geq \hat{d}_{i} \quad \forall i .
\end{aligned}
$$

Thus, $\Gamma_{i}^{2}$ is a parameter that determines the uncertainty budget determined by the model decisionmaker, and the variables $\tau_{i}^{2}$ and $\theta_{i}^{2}$ are auxiliary variables used in the Bertsimas-Sim model. Parameter $d_{i}$ represents demand nominal value, and parameter $\hat{d}_{i}$ represents the value of deviation from demand nominal value.

The same process was repeated for Constraints (13) and (14). Constraint (13) is given as follows:

$$
\sum_{v} \sum_{j, j \neq i} u_{j i v}+\tilde{s}_{l}=\sum_{v} \sum_{n, n \neq i} u_{i n v} \quad \forall i .
$$

In order to convert this equal constraint into an unequal one, the variable $d v_{i}^{3}$ was defined in such a way that the amount of penalty for deviating from the above constraint equation could be calculated. Parameters $d v c_{i}^{5}$ and $d v c_{i}^{6}$ were also defined as the penalty values for each unit of deviation from equality, respectively, in cases when the demand of the provinces would be greater than the nominal value and when less than the nominal value.

Therefore, the above constraint equation should be rewritten as follows:

$$
\begin{aligned}
& \left(\left(\sum_{v} \sum_{j, j \neq i} u_{j i v}+\tilde{s}_{l}\right)-\sum_{v} \sum_{n, n \neq i} u_{i n v}\right) d v c_{i}^{5} \leq d v_{i}^{3} \\
& \quad \forall i \\
& \left(\sum_{v} \sum_{n, n \neq i} u_{i n v}-\left(\sum_{v} \sum_{j, j \neq i} u_{j i v}+\tilde{s}_{l}\right)\right) d v c_{i}^{6} \leq d v_{i}^{3} \\
& \forall i .
\end{aligned}
$$

Now, according to the Bertsimas-Sim method, it can be said:

$$
\begin{gathered}
\left(\left(\sum_{v} \sum_{j, j \neq i} u_{j i v}+s_{i}\right)-\sum_{v} \sum_{n, n \neq i} u_{i n v}+\theta_{i}^{3}\right. \\
\left.+\tau_{i}^{3} \Gamma_{i}^{3}\right) d v c_{i}^{5} \leq d v_{i}^{3} \quad \forall i, \quad \Gamma_{i}^{3} \leq|1|, \\
\left(\sum_{v} \sum_{n, n \neq i} u_{i n v}-\left(\sum_{v} \sum_{j, j \neq i} u_{j i v}+s_{i}\right)+\theta_{i}^{3}\right. \\
\left.+\tau_{i}^{3} \Gamma_{i}^{3}\right) d v c_{i}^{6} \leq d v_{i}^{3} \quad \forall i, \quad \Gamma_{i}^{3} \leq|1|, \\
\theta_{i}^{3}+\tau_{i}^{3} \geq \hat{s}_{i} \\
\quad \forall i .
\end{gathered}
$$

Thus, $\Gamma_{i}^{3}$ is a parameter that determines the uncertainty budget set by the model decision-maker, and the variables $\tau_{i}^{3}$ and $\theta_{i}^{3}$ are auxiliary variables used in the Bertsimas-Sim model. Parameter $s_{i}$ represents the supply nominal value, and parameter $\hat{s}_{i}$ stands for the value of deviation from the supply nominal value. Constraint (14) is given as follows:

$$
\tilde{s}_{l}=\sum_{v} s_{i v}^{\prime} \quad \forall i .
$$

In order to convert this equal constraint into an unequal one, the variable $d v_{i}^{4}$ was defined in such a way that the penalty value for deviating from the above constraint equation could be calculated. Parameters $d v c_{i}^{7}$ and $d v c_{i}^{8}$ were also defined as the penalty values for each unit of deviation from equality, respectively, in cases when the supply of the provinces would be greater than the nominal value and when less than the nominal value.

Therefore, the above constraint equation should be rewritten as follows:

$$
\left(\sum_{v} s_{i v}^{\prime}-\tilde{s}_{l}\right) d v c_{i}^{7} \leq d v_{i}^{4} \quad \forall i
$$




$$
\left(\tilde{s}_{l}-\sum_{v} s_{i v}^{\prime}\right) d v c_{i}^{8} \leq d v_{i}^{4} \quad \forall i .
$$

Now, according to the Bertsimas-Sim method, it can be said:

$$
\begin{aligned}
& \left(\sum_{v} s_{i v}^{\prime}-s_{i}+\theta_{i}^{4}+\tau_{i}^{4} \Gamma_{i}^{4}\right) d v c_{i}^{7} \leq d v_{i}^{4} \\
& \forall i, \quad \Gamma_{i}^{4} \leq|1|, \\
& \left(s_{i}-\sum_{v} s_{i v}^{\prime}+\theta_{i}^{4}+\tau_{i}^{4} \Gamma_{i}^{4}\right) d v c_{i}^{8} \leq d v_{i}^{4} \\
& \forall i, \quad \Gamma_{i}^{4} \leq|1|, \\
& \theta_{i}^{4}+\tau_{i}^{4} \geq \hat{s}_{i} \quad \forall i .
\end{aligned}
$$

Thus, $\Gamma_{i}^{4}$ is a parameter that determines the uncertainty budget set by the model decision-maker, and the variables $\tau_{i}^{4}$ and $\theta_{i}^{4}$ are auxiliary variables used in the Bertsimas-Sim model. Parameter $s_{i}$ is the supply nominal value, while parameter $\hat{s}_{i}$ represents the value of deviation from supply nominal value.

Now, considering uncertainty, the certain model in the previous section is as follows:

$$
\begin{aligned}
\min z_{1}= & \sum_{i} e_{i} z_{i}+\sum_{v} \sum_{m} \sum_{n} c_{v} d i s_{n m v}\left(x_{n m v}+u_{n m v}\right) \\
& +\sum_{v} \sum_{m} \sum_{n} E c_{v} d i s_{n m v}\left(r_{n m v}\right)+\sum_{l=1}^{4} \sum_{i} d v_{i}^{l},
\end{aligned}
$$$$
\min z_{2}=\sum_{v} \sum_{m} \sum_{n} c o_{v} d i s_{n m v}\left(x_{n m v}+u_{n m v}\right)
$$$$
+\sum_{l=1}^{4} \sum_{i} d v_{i}^{l}
$$

s.t.:

Eq. (3)

$$
\begin{gathered}
\left(\sum_{v} \sum_{n, n \neq i} x_{n i v}-\left(\sum_{v} \sum_{j, j \neq i} x_{i j v}+d_{i}\right)+\theta_{i}^{1}\right. \\
\left.+\tau_{i}^{1} \Gamma_{i}^{1}\right) d v c_{i}^{1} \leq d v_{i}^{1} \quad \forall i, \quad \Gamma_{i}^{1} \leq|1|, \\
\left(\left(\sum_{v} \sum_{j, j \neq i} x_{i j v}+d_{i}\right)-\sum_{v} \sum_{n, n \neq i} x_{n i v}+\theta_{i}^{1}\right.
\end{gathered}
$$

$$
\left.+\tau_{i}^{1} \Gamma_{i}^{1}\right) d v c_{i}^{2} \leq d v_{i}^{1} \quad \forall i, \quad \Gamma_{i}^{1} \leq|1|,
$$

$\theta_{i}^{1}+\tau_{i}^{1} \geq \hat{d}_{i}$

$\forall i$,

$$
\begin{aligned}
& \left(\sum_{v} d_{i v}^{\prime}-d_{i}+\theta_{i}^{2}+\tau_{i}^{2} \Gamma_{i}^{2}\right) d v c_{i}^{3} \leq d v_{i}^{2} \\
& \forall i, \quad \Gamma_{i}^{2} \leq|1|, \\
& \left(d_{i}-\sum_{v} d_{i v}^{\prime}+\theta_{i}^{2}+\tau_{i}^{2} \Gamma_{i}^{2}\right) d v c_{i}^{4} \leq d v_{i}^{2} \\
& \forall i, \quad \Gamma_{i}^{2} \leq|1|, \\
& \theta_{i}^{2}+\tau_{i}^{2} \geq \hat{d}_{i} \quad \forall i,
\end{aligned}
$$$$
\text { Eqs. }(6)-(12)
$$$$
\begin{aligned}
& \left(\left(\sum_{v} \sum_{j, j \neq i} u_{j i v}+s_{i}\right)-\sum_{v} \sum_{n, n \neq i} u_{i n v}+\theta_{i}^{3}\right. \\
& \left.+\tau_{i}^{3} \Gamma_{i}^{3}\right) d v c_{i}^{5} \leq d v_{i}^{3} \quad \forall i, \quad \Gamma_{i}^{3} \leq|1|,
\end{aligned}
$$$$
\left(\sum_{v} \sum_{n, n \neq i} u_{i n v}-\left(\sum_{v} \sum_{j, j \neq i} u_{j i v}+s_{i}\right)+\theta_{i}^{3}\right.
$$$$
\left.+\tau_{i}^{3} \Gamma_{i}^{3}\right) d v c_{i}^{6} \leq d v_{i}^{3} \quad \forall i, \quad \Gamma_{i}^{3} \leq|1|,
$$$$
\theta_{i}^{3}+\tau_{i}^{3} \geq \hat{s}_{i}
$$$$
\forall i,
$$$$
\left(\sum_{v} s_{i v}^{\prime}-s_{i}+\theta_{i}^{4}+\tau_{i}^{4} \Gamma_{i}^{4}\right) d v c_{i}^{7} \leq d v_{i}^{4}
$$$$
\forall i, \quad \Gamma_{i}^{4} \leq|1|,
$$$$
\left(s_{i}-\sum_{v} s_{i v}^{\prime}+\theta_{i}^{4}+\tau_{i}^{4} \Gamma_{i}^{4}\right) d v c_{i}^{8} \leq d v_{i}^{4}
$$$$
\forall i, \quad \Gamma_{i}^{4} \leq|1|,
$$

$\theta_{i}^{4}+\tau_{i}^{4} \geq \hat{s}_{i}$

$\forall i$

Eqs. (15) - (23)

$o_{p}, x_{n m v}, d_{i v}^{\prime}, w_{p}, u_{n m v}, s_{i v}^{\prime}, d v_{i}^{1}, d v_{i}^{2}, d v_{i}^{3}, d v_{i}^{4}, \theta_{i}^{1}$,

$$
\theta_{i}^{2}, \theta_{i}^{3}, \theta_{i}^{4}, \tau_{i}^{1}, \tau_{i}^{2}, \tau_{i}^{3}, \tau_{i}^{4} \geq 0 \quad \forall p, n, m, v, i,
$$


Eq. (25).

\section{Problem solving}

In this method, epsilon constraint method ( $\varepsilon$-constraint method) is used to prove the multi-objective potential of the model with non-aligned objectives. The mentioned method is one of the well-known approaches to multi-objective problems, i.e., solving all these problems through conveying all the objectives except one in each stage. Therefore, through the method of constraint $\varepsilon$, the Pareto Boundary is created.

Consider the following multi-objective model:

$$
\min \left(f_{1}(x), f_{2}(x), \cdots, f_{n}(x)\right) \text {. }
$$

s.t:

$x \in S$,

where $x$ is the vector of the decision variables; $f_{1}(x), f_{2}(x), \ldots, f_{n}(x)$ are the objective functions and $S$ is the feasible area.

The steps of the Epsilon constraint method are as follows:

1. Consider one of the objective functions as the main objective function;

2. Fulfill the objectives each time with one of the functions, trying to obtain the optimal value for each objective function;

3. Divide the interval between the two optimal values of the sub-objective functions into a predefined number and form a table of values for $\varepsilon_{2} \cdots \varepsilon_{n}$;

4. Each time, solve the problem with the main objective function with each value of $\varepsilon_{2} \cdots \varepsilon_{n}$;

5. Report the Pareto answers found.

Given the above steps, the mathematical model is as follows:

$$
\begin{aligned}
& \min f_{1}(x) \\
& f_{2}(x) \leq \varepsilon_{2}
\end{aligned}
$$

$$
f_{n}(x) \leq \varepsilon_{n} .
$$

In the case of the problem under study, by considering the objective function $z_{1}$ (minimizing the total cost of the system) as the main objective function and the objective function $z_{2}$ (minimizing $\mathrm{CO}_{2}$ pollutant) as a constraint, the equation is converted into Eq. (74):

$$
\begin{gathered}
\sum_{v} \sum_{m} \sum_{n} c o_{v} d i s_{n m v}\left(x_{n m v}+u_{n m v}\right) \\
+\sum_{l=1}^{4} \sum_{i} d v_{i}^{l} \leq \varepsilon_{2} .
\end{gathered}
$$

To solve the model, real data on the amount of imports and exports from 31 provinces of Iran that are imported into or out of the country through the seaports of Imam Khomeini, Shahid Rajaee, and Shahid Beheshti seaports has been used. It should be noted that there are only two modes of road and rail transport on the transport route. The set $p\left(p \in\left\{p_{1}, p_{2}, p_{3}\right\}\right)$ consists of southern seaports of Iran, namely Imam Khomeini Seaport, Shahid Rajaei Seaport, and Shahid Beheshti Seaport; and the set $i, j \in\{1,2, \cdots, 31\}$ comprises the provinces of Iran shown in Table A.1 in the Appendix. The set $n, m \in\left\{1,2, \cdots, 31, p_{1}, p_{2}, p_{3}\right\}$ comprises nodes that exchange goods with each other; the exchange is done through the transportation modes $v \in\{1,2\}$ which are road and rail transportation modes, respectively. The parameters $d_{i}$ and $s_{i}$, which are the demand and supply quantities of the provinces, can be found in Tables A.2 and A.3 in the Appendix. The parameters of the transfer cost and $\mathrm{CO}_{2}$ emission rates are listed in Table A.4. Moreover, the value of $\hat{d}_{i}$ shown in Table A.5 is equal to the value of deviation from the nominal value of demand in the $i$ 'th province, and the value of $\hat{s}_{i}$ shown in Table A.6 is equal to the value of deviation from the nominal value of supply in the $i$ 'th province; these are both about $10 \%$ of the nominal value. The penalty for deviation from the equal constraints previously described is shown in Table A.7 in the Appendix. In addition, $\Gamma_{i}^{1}=\Gamma_{i}^{2}=$ $\Gamma_{i}^{3}=\Gamma_{i}^{4}=1$ is considered to be the most pessimistic state, and each province is in the most pessimistic state of uncertainty.

According to the provided description, the uncertainty model is solved using GAMS software for a problem with the mentioned parameters; therefore, the following values are obtained. It should be noted that to form the Pareto Layer, the number of iterations taken into account is 20 . The results of the basic model solution are shown in Table A.8 in the Appendix. According to the results, the better the condition of the first objective function, the worse the second objective function. The results of the model variables for the first and 20th iterations are shown in Figures 1 and 2, respectively. As introduced earlier, $p_{1}$, $p_{2}$, and $p_{3}$ represent Imam Khomeini, Shahid Rajaei, and Shahid Beheshti ports, respectively. At the first iteration, these three mentioned ports manage the transfers of 29178, 9372, and 959 thousand tons of imported goods and the transfers of 110880, 17028, and 4092 thousand tons of exported goods, respectively. Therefore, inland terminals shall be established in provinces $28,26,25,17,16,11,4$. At the 20th iteration, $p_{1}, p_{2}$, and $p_{3}$ ports manage the transfers of 32285 , 6265 , and 959 thousand tons of imported goods as well as 111804,7788 , and 12408 thousand tons of exported goods, respectively. At the 20 th iteration, no terminals would be established. 


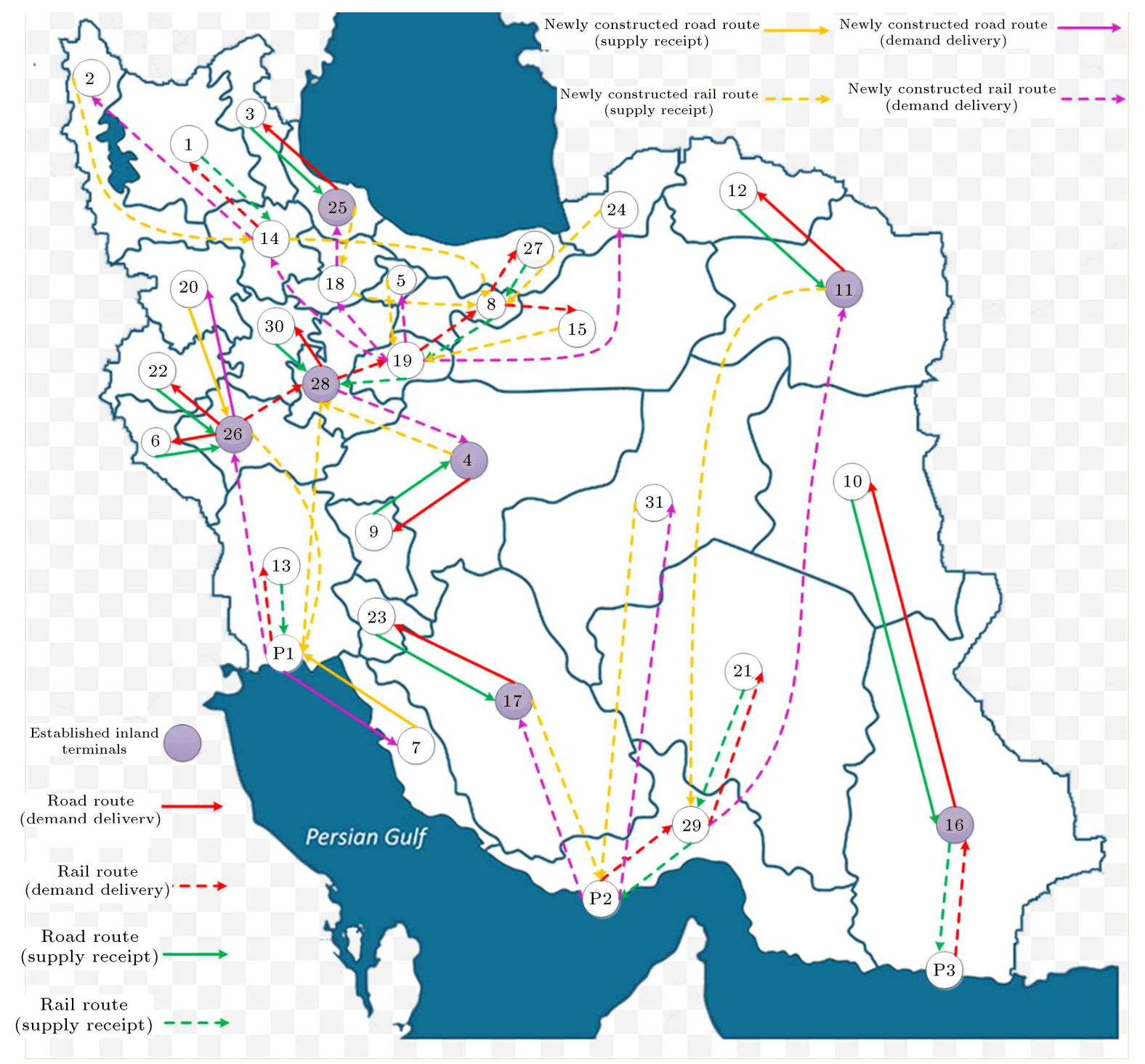

Figure 1. Results of the first iteration.

Since the first objective function is to minimize costs and the second objective function is to minimize pollutants, at the first iteration which involves the second best objective function and the first worst objective function, the model tries to reduce $\mathrm{CO}_{2}$ as much as possible using rail routes. As a result, since there are no rail routes in many provinces and road routes must be used, there would be a shift in transportation modes; therefore, an inland terminal should be established that boost the first objective function. On the contrary, as the number of iterations increases, the cost optimization model preferably uses road routes in order to prevent establishing more inland terminals and yet, produces more $\mathrm{CO}_{2}$. The deviation penalty from the constraints would be added to both objective functions if it was added just to the first objective function. Due to the minimization of the second objective function, the model at the first itera- tions could not meet the supply/demand needs of the provinces. Therefore, the results of the model would be useless, because if deviation from the constraints was equal, both functions would experience penalty and increase at the same time. The results of the above model provide the amounts of goods transported in each of the available and constructed routes (Figures 1 and 2).

As stated before, at the first iteration (Figure 1), the model that prioritizes the second objective function aimed at decreasing $\mathrm{CO}_{2}$ emissions attempts to use fewer rail routes. Therefore, considering that there is no possibility of constructing new rail routes in some provinces and there is no other way but to use road routes, 7 inland terminals must be established as a result. In addition to the increase in the number of iterations, the model seeks to minimize the first objective function. The model preferably uses more 


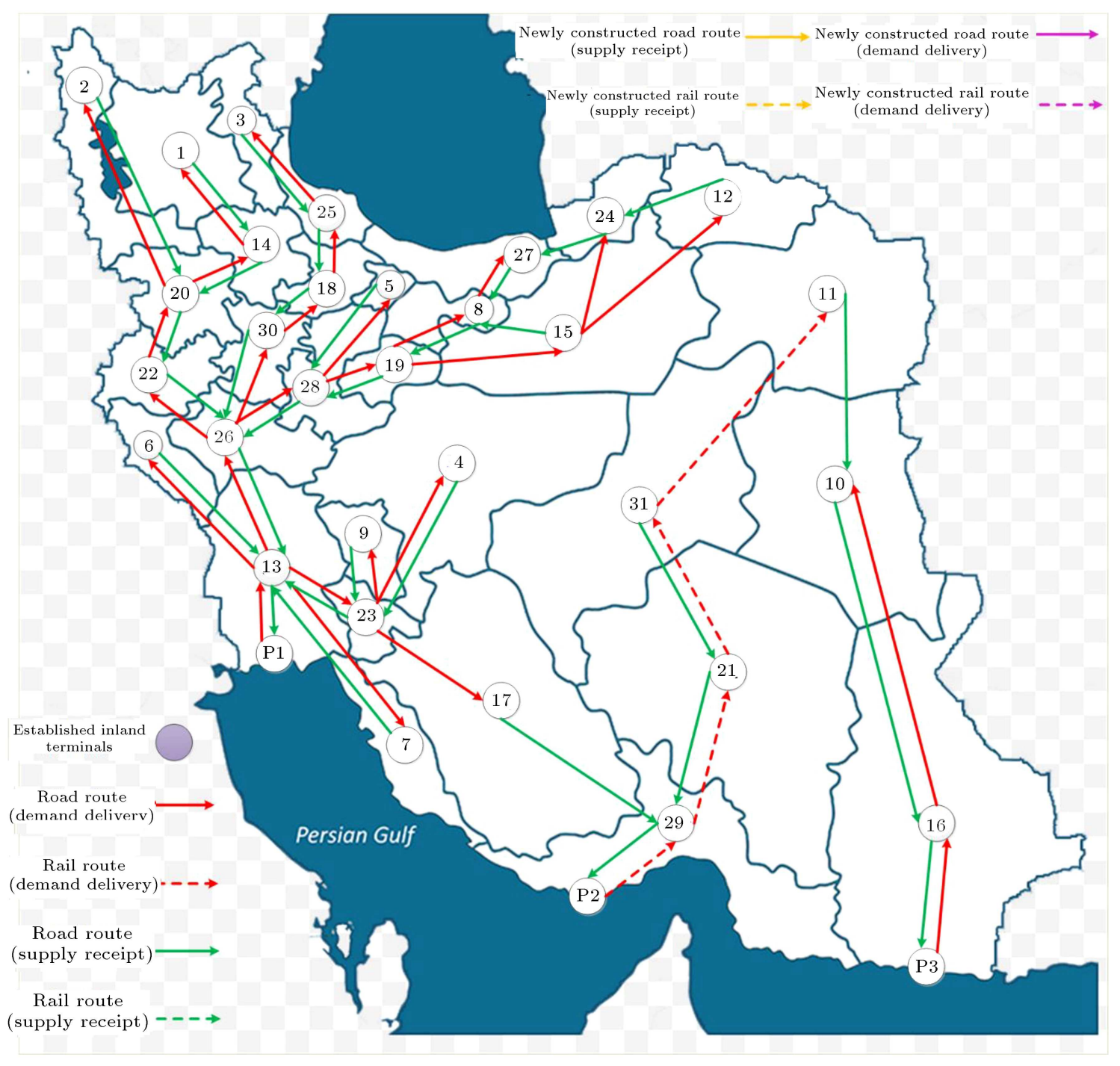

Figure 2. Results of the 20th iteration.

road routes to reduce the costs and to construct less routes and inland terminals. At the 20th iteration (Figure 2), no terminals were established, while only four routes were used for import and export. In this case, road roots used for import and export are 27 and 31, respectively. Table 1 shows the number of inland terminals established, number of rail and road routes used, and number of new rail and road routes constructed at each iteration.

\section{Managerial insight}

By solving the problem with different parameters, important points that should be considered in defining the parameters were obtained:

- Parameters $\Gamma_{i}^{1}, \Gamma_{i}^{2}, \Gamma_{i}^{3}, \Gamma_{i}^{4} \leq|1|$ could be allocated at the interval of $[-1,1]$. If the value is 0 , the model reaches a certain state with a nominal value of demand and supply; if it is 1 , the model considers the most pessimistic state of robust; and if it is 1 , the model considers the most optimistic state of robustness (The model is currently solved with the values $\Gamma_{i}^{1}, \Gamma_{i}^{2}, \Gamma_{i}^{3}, \Gamma_{i}^{4}=1$;

- Since the amount of penalty $\left(d v c_{i}^{1-8}\right)$ for deviating from all the constraints is considered 100,000 in this solved model, the model attempts to send/receive the same amount of goods in demand and supply.

In Constraints (50) and (51), if the value of $d v c_{i}^{1}$ is much higher than $d v c_{i}^{2}$ and in Constraints (56) and (57), if the value of $d v c_{i}^{3}$ is much higher than $d v c_{i}^{4}$, it is more likely that the model would consider the minimum demand (less than nominal value) for each province and delivery would be done according to this minimum demand. Therefore, each province may suffer from deficit. This is while if these two costs were considered equal, the model itself would decide on the 
Table 1. Number of new rail and road routes constructed at each iteration.

\begin{tabular}{|c|c|c|c|c|c|c|c|c|c|}
\hline \multirow[b]{2}{*}{ Iteration } & \multicolumn{2}{|c|}{$\begin{array}{c}\text { Number of } \\
\text { road routes } \\
\text { (available) }\end{array}$} & \multicolumn{2}{|c|}{$\begin{array}{l}\text { Number of } \\
\text { road routes } \\
\text { (newly } \\
\text { constructed) }\end{array}$} & \multicolumn{2}{|c|}{$\begin{array}{l}\text { Number of } \\
\text { rail routes } \\
\text { (available) }\end{array}$} & \multicolumn{2}{|c|}{$\begin{array}{c}\text { Number of } \\
\text { rail routes } \\
\text { (newly } \\
\text { constructed) }\end{array}$} & \multirow[t]{2}{*}{$\begin{array}{l}\text { Number of } \\
\text { inland } \\
\text { terminals } \\
\text { established }\end{array}$} \\
\hline & Import & Export & Import & Export & Import & Export & Import & Export & \\
\hline 1 & 8 & 8 & 2 & 2 & 10 & 8 & 11 & 13 & 7 \\
\hline 2 & 16 & 21 & 0 & 1 & 19 & 20 & 0 & 0 & 7 \\
\hline 3 & 13 & 14 & 0 & 0 & 20 & 19 & 0 & 0 & 6 \\
\hline 4 & 14 & 16 & 0 & 0 & 19 & 17 & 0 & 0 & 4 \\
\hline 5 & 16 & 14 & 0 & 0 & 18 & 19 & 0 & 0 & 6 \\
\hline 6 & 21 & 15 & 0 & 0 & 13 & 18 & 0 & 0 & 3 \\
\hline 7 & 18 & 21 & 0 & 0 & 19 & 16 & 0 & 0 & 2 \\
\hline 8 & 27 & 24 & 0 & 0 & 9 & 14 & 0 & 0 & 3 \\
\hline 9 & 20 & 24 & 0 & 0 & 19 & 15 & 0 & 0 & 0 \\
\hline 10 & 26 & 16 & 0 & 0 & 5 & 18 & 0 & 0 & 3 \\
\hline 11 & 25 & 23 & 0 & 0 & 7 & 10 & 0 & 0 & 2 \\
\hline 12 & 25 & 23 & 0 & 0 & 10 & 10 & 0 & 0 & 2 \\
\hline 13 & 27 & 22 & 0 & 0 & 4 & 14 & 0 & 0 & 0 \\
\hline 14 & 30 & 22 & 0 & 0 & 2 & 14 & 0 & 0 & 0 \\
\hline 15 & 16 & 26 & 0 & 0 & 20 & 5 & 0 & 0 & 1 \\
\hline 16 & 24 & 28 & 0 & 0 & 15 & 4 & 0 & 0 & 0 \\
\hline 17 & 31 & 28 & 0 & 0 & 0 & 5 & 0 & 0 & 0 \\
\hline 18 & 31 & 28 & 0 & 0 & 0 & 4 & 0 & 0 & 0 \\
\hline 19 & 27 & 31 & 0 & 0 & 4 & 0 & 0 & 0 & 0 \\
\hline 20 & 27 & 31 & 0 & 0 & 4 & 0 & 0 & 0 & 0 \\
\hline
\end{tabular}

deficit or surplus. In the third case, if the value of $d v c_{i}^{2}$ is much higher than $d v c_{i}^{1}$ in Constraints (50) and (51) and if the value of $d v c_{i}^{4}$ is much higher than $d v c_{i}^{3}$ in Constraints (56) and (57), it is more likely that the model would consider maximum demand (more than nominal value) for each province and delivery would be done according to this maximum demand. Therefore, each province may suffer from surplus.

If the value of $d v c_{i}^{5}$ is much higher than $d v c_{i}^{6}$ in Constraints (62) and (63) and if the value of $d v c_{i}^{7}$ is much higher than $d v c_{i}^{8}$ in Constraints (68) and (69), it is more likely that the model would consider the minimum supply (less than nominal value) for each province and receipt would be done according to this minimum supply. Therefore, each province may suffer from deficit. This is while if these two costs were considered equal, the model itself would decide on the deficit or surplus. In the third case, if the value of $d v c_{i}^{6}$ is much higher than $d v c_{i}^{5}$ in Constraints (62) and (63) and if the value of $d v c_{i}^{8}$ is much higher than $d v c_{i}^{7}$ in Constraints (56) and (57), it is more likely that the model would consider the maximum supply (more than nominal value) for each province and receipt would be done according to this maximum supply. Therefore, each province may suffer from surplus.

\section{Conclusion}

Given that hinterland constitutes the lion's share of the logistics cost, studying the design of a port hinterland 
freight distribution network has received considerable attention by researchers. However, strategic studies with the objective to determine means to design and use transportation infrastructures have received minor attention. Various parameters such as geographical distribution of hinterland regions in terms of supply and demand, existing infrastructure (roads, railways, and inland terminals), ports that are gateway to the distribution of export/import, different costs that each of these factors imposes, and environmental sustainability issue, which is of great importance to researchers in today's world, play major roles in designing an optimal freight distribution network.

Given the importance of uncertainty concepts in the formation and functioning of supply chains featuring various applications in the real world, this article presented a model of port hinterland freight distribution network problem, including a robust optimization based on the best possible information obtained in recent studies. The design of a port-hinterland distribution network including intermodal transportation, establishment of inland terminal where mode change occurs, and the possibility of constructing new routes in each mode of transportation was investigated. Iran was considered as the case study and its provinces were assumed to be supply/demand nodes or origin/final destination of goods. A certain and robust multiobjective and intermodal model (for uncertainty conditions) was developed in order to deliver imported goods to provinces and receive export goods from them. The model assumes that in order to transport goods, the existing rail/road routes can be used and new rail/road routes be constructed, as well. Therefore, in the first objective function, the model attempted to minimize transportation costs (for transfer of imported/exported goods) as well as the cost of construction of new inland terminals and routes. The second objective function sought to minimize the $\mathrm{CO}_{2}$ released during freight transportation. Given that real-life problems are uncertain, the demand for imported goods and supply of exported goods in each province was considered uncertain. Therefore, robust optimization method was employed to deal with this uncertainty. After modeling, the actual data of the goods imported to and exported from Iran were collected and solved for an uncertain model in GAMS software. Then, results were analyzed.

This research is recommended as future research by considering capacity constraints on routes or developing an innovative algorithm or a certain solution to solve large-scale problems. Geopolitically, Iran is at a crossroad and has been influenced by various international corridors, such as Silk Road. It is recommended that future studies will consider the effect of imported/exported transit goods from these routes on the determination of routes or construction points of inland terminals. This research can be extended to all the areas that benefit from port for goods distribution. Many countries in open-waters neighborhood have strategic concerns for distribution of goods and achievement of optimal conditions. Upon the addition of the desired conditions and constraints, this model can be developed.

\section{References}

1. Parola, F., Risitano, M., Ferretti, M., et al. "The drivers of port competitiveness: a critical review", Transport Reviews, 37, pp. 116-138 (2017).

2. López-Navarro, M.Á. "Environmental factors and intermodal freight transportation: Analysis of the decision bases in the case of spanish motorways of the sea", Sustainability, 6(3), pp. 1544-1566 (2014).

3. Sdoukopoulos, E. and Boile, M. "Port-hinterland concept evolution: A critical review", J. Transp. Geogr., 86, p. 102775 (2020).

4. Kim, N.S. and Van Wee, B. "Toward a better methodology for assessing $\mathrm{CO}_{2}$ emissions for intermodal and truck-only freight systems: A European case study", Int. J. Sustain. Transp., 8(3), pp. 177-201 (2014).

5. Halim, R.A., Kwakkel, J.H., and Tavasszy, L.A. "A strategic model of port-hinterland freight distribution networks", Transp. Res. Part E Logist. Transp. Rev., 95, pp. 368-384 (2016).

6. Dooms, M., Haezendonck, E., and Verbeke, A. "Towards a meta-analysis and toolkit for port-related socio-economic impacts: a review of socio-economic impact studies conducted for seaports", Marit. Policy Manag., 42(5), pp. 459-480 (2015).

7. Veenstra, A., Zuidwijk, R., and Van Asperen, E. "The extended gate concept for container terminals: Expanding the notion of dry ports", Marit. Econ. Logist., 14(1), pp. 14-32 (2012).

8. Van den Berg, R. and De Langen, P.W. "Towards an 'inland terminal centred'value proposition", Marit. Policy Manag., 42(5), pp. 499-515 (2015).

9. Monios, J. "The role of inland terminal development in the hinterland access strategies of Spanish ports", Res. Transp. Econ., 33(1), pp. 59-66 (2011).

10. Panova, Y. and Hilmola, O.-P. "Justification and evaluation of dry port investments in Russia", Res. Transp. Econ., 51, pp. 61-70 (2015).

11. Woodburn, A. "An analysis of rail freight operational efficiency and mode share in the British porthinterland container market", Transp. Res. Part D Transp. Environ., 51, pp. 190-202 (2017).

12. Roso, V. "Sustainable intermodal transport via dry ports-importance of directional development", World Rev. Intermodal Transp. Res., 4(2-3), pp. 140-156 (2013).

13. Nguyen, L.C. and Notteboom, T. "The relations between dry port characteristics and regional port- 
hinterland settings: findings for a global sample of dry ports", Maritime Policy \& Management., 46, pp. 2442 (2019).

14. Khaslavskaya, A. and Roso, V. "Dry ports: research outcomes, trends, and future implications", Maritime Economics \& Logistics, 22(2), pp. 1-28 (2020).

15. Lam, J.S.L. and Gu, Y. "A market-oriented approach for intermodal network optimisation meeting cost, time and environmental requirements", Int. J. Prod. Econ., 171, pp. 266-274 (2016).

16. Wang, C. "Optimization of hub-and-spoke two-stage logistics network in regional port cluster", Syst. Eng. Pract., 28(9), pp. 152-158 (2008).

17. Mingjun, J.I. and Maoying, H.E. "Optimization of two-stage port logistics network of dynamic hinterland based on bi-level programming model", J. Transp. Syst. Eng. Inf. Technol., 10(6), pp. 89-94 (2010).

18. Iannone, F. and Thore, S. "An economic logistics model for the multimodal inland distribution of maritime containers", Int. J. Transp. Econ. Internazionale di Econ. Dei Trasp., pp. 281-326 (2010).

19. Kim, N., Janic, M., and Van Wee, B. "Trade-off between carbon dioxide emissions and logistics costs based on multiobjective optimization", Transp. Res. Rec. J. Transp. Res. Board, 2139, pp. 107-116 (2009).

20. Rahimi, M., Asef-Vaziri, A., and Harrison, R. "An inland port location-allocation model for a regional intermodal goods movement system", Marit. Econ. Logist., 10(4), pp. 362-379 (2008).

21. Feng, X., Zhang, Y., Li, Y., et al. "A locationallocation model for seaport-dry port system optimization", Discret. Dyn. Nat. Soc., 2013, pp. 1-29 (2013).

22. Lättilä, L., Henttu, V., and Hilmola, O.-P. "Hinterland operations of sea ports do matter: Dry port usage effects on transportation costs and $\mathrm{CO}_{2}$ emissions", Transp. Res. Part E Logist. Transp. Rev., 55, pp. 2342 (2013).

23. Henttu, V. and Hilmola, O.-P. "Financial and environmental impacts of hypothetical finish dry port structure", Res. Transp. Econ., 33(1), pp. 35-41 (2011).

24. Wang, C., Chen, Q., and Huang, R. "Locating dry ports on a network: a case study on Tianjin Port", Marit. Policy Manag., 45(1), pp. 71-88 (2018).

25. Chang, Z., Notteboom, T., and Lu, J. "A two-phase model for dry port location with an application to the port of Dalian in China", Transp. Plan. Technol., 38(4), pp. 442-464 (2015).

26. Zhang, M., Janic, M., and Tavasszy, L.A. "A freight transport optimization model for integrated network, service, and policy design", Transp. Res. Part E Logist. Transp. Rev., 77, pp. 61-76 (2015).
27. Aregall, M.G., Bergqvist, R., and Monios, J. "A global review of the hinterland dimension of green port strategies", Transp. Res. Part D Transp. Environ., 59, pp. 23-34 (2018).

28. Hu, Q., Corman, F., Wiegmans, B., et al. "A tabu search algorithm to solve the integrated planning of container on an inter-terminal network connected with a hinterland rail network", Transp. Res. Part C Emerg. Technol., 91, pp. 15-36 (2018).

29. Santos, T.A. and Soares, C.G. "Container terminal potential hinterland delimitation in a multi-port system subject to a regionalization process", J. Transp. Geogr., 75, pp. 132-146 (2019).

30. Resat, H.G. and Turkay, M. "A discrete-continuous optimization approach for the design and operation of synchromodal transportation networks", Comput. Ind. Eng., 130, pp. 512-525 (2019).

31. Liu, P., Liu, C., Du, J., et al. "A system dynamics model for emissions projection of hinterland transportation", J. Clean. Prod., 218, pp. 591-600 (2019).

32. Van Nguyen, T., Zhang, J., Zhou, L., et al. "A datadriven optimization of large-scale dry port location using the hybrid approach of data mining and complex network theory", Transp. Res. Part E Logist. Transp. Rev., 134, p. 101816 (2020).

33. Jiang, J., Zhang, D., Meng, Q., et al. "Regional multimodal logistics network design considering demand uncertainty and $\mathrm{CO}_{2}$ emission reduction target: A system-optimization approach", J. Clean. Prod., 248, p. 119304 (2020).

34. Soyster, A.L. "Convex programming with set-inclusive constraints and applications to inexact linear programming", Oper. Res., 21(5), pp. 1154-1157 (1973).

35. Ben-Tal, A. and Nemirovski, A. "Robust convex optimization", Math. Oper. Res., 23(4), pp. 769-805 (1998).

36. Bertsimas, D. and Sim, M. "The price of robustness", Oper. Res., 52(1), pp. 35-53 (2004).

37. Bertsimas, D. and Thiele, A. "A robust optimization approach to inventory theory", Oper. Res., 54(1), pp. 150-168 (2006).

38. Golsefidi A.H. and Akbari Jokar, M.R. "A robust optimization approach for the production-inventoryrouting problem with simultaneous pickup and delivery", Comput. Ind. Eng., p. 106388 (2020).

\section{Appendix}

Supplementary data to this article related to Tables A.1 to A.4 is provided from the yearbooks of Iran Ministry of Roads and Urban Development and the Railway Organization during the years 2014 to 2019. Tables A.5 to A. 8 are related to the output of the model and the values considered to solve the model, which are explained in the model. 
Table A.1. Set of provinces of the country.

\begin{tabular}{|c|c|c|c|c|c|c|c|}
\hline$i$ & 1 & 2 & 3 & 4 & 5 & 6 & 7 \\
\hline Province name & $\begin{array}{c}\text { East } \\
\text { Azerbayjan }\end{array}$ & $\begin{array}{c}\text { West } \\
\text { Azerbayjan }\end{array}$ & Ardebil & Isfahan & Alborz & Ilam & Boushehr \\
\hline$i$ & 8 & 9 & 10 & 11 & 12 & 13 & 14 \\
\hline Province name & Tehran & $\begin{array}{l}\text { Chaharmahal } \\
\text { and Bakhtiari }\end{array}$ & $\begin{array}{c}\text { South } \\
\text { Khorasan }\end{array}$ & $\begin{array}{c}\text { Razavi } \\
\text { Khorasan }\end{array}$ & $\begin{array}{c}\text { North } \\
\text { Khorasan }\end{array}$ & Khuzestan & Zanjan \\
\hline$i$ & 15 & 16 & 17 & 18 & 19 & 20 & 21 \\
\hline Province name & Semnan & $\begin{array}{l}\text { Sistan and } \\
\text { Baluchestan }\end{array}$ & Fars & Qazvin & Qom & Kurdestan & Kerman \\
\hline$i$ & 22 & 23 & 24 & 25 & 26 & 27 & 28 \\
\hline Province name & Kermanshah & $\begin{array}{l}\text { Kohgiluyeh and } \\
\text { Boyer-Ahmad }\end{array}$ & Golestan & Guilan & Lorestan & Mazandaran & Markazi \\
\hline$i$ & 29 & 30 & 31 & & & & \\
\hline Province name & Hormozgan & Hamedan & Yazd & & & & \\
\hline
\end{tabular}

Table A.2. $d_{i}$ value (thousand tones).

\begin{tabular}{ccccccccccccccccc}
\hline $\boldsymbol{i}$ & 1 & 2 & 3 & 4 & 5 & 6 & 7 & 8 & 9 & 10 & 11 & 12 & 13 & 14 & 15 & 16 \\
$\boldsymbol{d}_{\boldsymbol{i}}$ & 1907 & 1595 & 1129 & 2535 & 1322 & 285 & 1026 & 6474 & 464 & 374 & 3140 & 421 & 2297 & 515 & 343 & 585 \\
$\boldsymbol{i}$ & 17 & 18 & 19 & 20 & 21 & 22 & 23 & 24 & 25 & 26 & 27 & 28 & 29 & 30 & 31 & \\
$\boldsymbol{d}_{\boldsymbol{i}}$ & 2340 & 620 & 632 & 784 & 1544 & 936 & 347 & 913 & 1236 & 858 & 1603 & 858 & 1026 & 846 & 554 & \\
\hline
\end{tabular}

Table A.3. $s_{i}$ value (thousand tones).

\begin{tabular}{|c|c|c|c|c|c|c|c|c|c|c|c|c|c|c|c|c|}
\hline$i$ & 1 & 2 & 3 & 4 & 5 & 6 & 7 & 8 & 9 & 10 & 11 & 12 & 13 & 14 & 15 & 16 \\
\hline $\boldsymbol{s}_{i}$ & 5544 & 4356 & 1716 & 10296 & 2376 & 264 & 21384 & 32208 & 660 & 3300 & 8316 & 528 & 12936 & 1584 & 2376 & 792 \\
\hline$i$ & 17 & 18 & 19 & 20 & 21 & 22 & 23 & 24 & 25 & 26 & 27 & 28 & 29 & 30 & 31 & \\
\hline$s_{i}$ & 2772 & 1848 & 1320 & 1188 & 1452 & 1584 & 396 & 1188 & 1056 & 924 & 1584 & 3696 & 1716 & 792 & 1848 & \\
\hline
\end{tabular}

Table A.4. Model cost parameters.

\begin{tabular}{lcc}
\hline \multicolumn{1}{c}{ Parameter } & Unit & Amount \\
\hline$c_{1}:$ Amount of transport costs by rail transport mode & dollar $/$ ton $/ \mathrm{km}$ & $0.024 \$$ \\
$c_{2}:$ Amount of transport costs by rail transport mode & dollar $/$ ton $/ \mathrm{km}$ & $0.021 \$$ \\
$c_{1}:$ Amount of $\mathrm{CO}_{2}$ produced by road transport mode & $\mathrm{gr} / \mathrm{ton} / \mathrm{km}$ & 62 \\
$\mathrm{co}_{2}:$ Amount of $\mathrm{CO}_{2}$ produced by rail transport mode & $\mathrm{gr} / \mathrm{ton} / \mathrm{km}$ & 22 \\
$E c_{1}:$ Cost of establishing each kilometer of one-way & dollar $/ \mathrm{km}$ & 5.63 million $\$$ \\
$\quad$ transport route with road transport mode & & \\
$E c_{2}:$ Cost of establishing each kilometer of one-way & dollar $/ \mathrm{km}$ & 1.88 million $\$$ \\
$\quad$ transport route with rail transport mode & & $15600000 \$$ \\
$e_{i}:$ Cost of establishing $i$ 'th inland terminal & & \\
\hline
\end{tabular}

Table A.5. $\hat{d}_{i}$ amount of deviation from demand nominal value of the $i$ th province (thousand tones) (about $10 \%$ of nominal value is defined).

\begin{tabular}{ccccccccccccccccc}
\hline $\boldsymbol{i}$ & 1 & 2 & 3 & 4 & 5 & 6 & 7 & 8 & 9 & 10 & 11 & 12 & 13 & 14 & 15 & 16 \\
$\hat{\boldsymbol{d}}_{\boldsymbol{i}}$ & 191 & 160 & 113 & 254 & 132 & 29 & 103 & 647 & 46 & 37 & 314 & 42 & 230 & 52 & 34 & 59 \\
$\boldsymbol{i}$ & 17 & 18 & 19 & 20 & 21 & 22 & 23 & 24 & 25 & 26 & 27 & 28 & 29 & 30 & 31 & \\
$\hat{\boldsymbol{d}}_{\boldsymbol{i}}$ & 234 & 62 & 63 & 78 & 154 & 94 & 35 & 91 & 124 & 86 & 160 & 86 & 103 & 85 & 55 & \\
\hline
\end{tabular}

Table A.6. $\hat{s}_{i}$ amount of deviation from supply nominal value of the $i$ th province (thousand tones) (about $10 \%$ of nominal value is defined).

\begin{tabular}{ccccccccccccccccc}
\hline $\boldsymbol{i}$ & 1 & 2 & 3 & 4 & 5 & 6 & 7 & 8 & 9 & 10 & 11 & 12 & 13 & 14 & 15 & 16 \\
$\boldsymbol{s}_{\boldsymbol{i}}$ & 554 & 436 & 172 & 1030 & 238 & 26 & 2138 & 3221 & 66 & 330 & 832 & 53 & 1294 & 158 & 238 & 79 \\
$\boldsymbol{i}$ & 17 & 18 & 19 & 20 & 21 & 22 & 23 & 24 & 25 & 26 & 27 & 28 & 29 & 30 & 31 & \\
$\boldsymbol{s}_{\boldsymbol{i}}$ & 277 & 185 & 132 & 119 & 145 & 158 & 40 & 119 & 106 & 92 & 158 & 370 & 172 & 79 & 185 & \\
\hline
\end{tabular}


Table A.7. Values of penalty deviation parameter from equal constraints.

\begin{tabular}{cccccccccccc}
\hline $\boldsymbol{i}$ & 1 & 2 & 3 & 4 & 5 & 6 & 7 & 8 & 9 & 10 & 11 \\
$\boldsymbol{d} \boldsymbol{v} \boldsymbol{c}_{\boldsymbol{i}}^{\mathbf{1}-\mathbf{8}}$ & 100000 & 100000 & 100000 & 100000 & 100000 & 100000 & 100000 & 100000 & 100000 & 100000 & 100000 \\
$\boldsymbol{i}$ & 12 & 13 & 14 & 15 & 16 & 17 & 18 & 19 & 20 & 21 & 22 \\
$\boldsymbol{d} \boldsymbol{v} \boldsymbol{c}_{\boldsymbol{i}}^{\mathbf{1}-\mathbf{8}}$ & 100000 & 100000 & 100000 & 100000 & 100000 & 100000 & 100000 & 100000 & 100000 & 100000 & 100000 \\
$\boldsymbol{i}$ & 23 & 24 & 25 & 26 & 27 & 28 & 29 & 30 & 31 & & \\
$\boldsymbol{d v}_{\boldsymbol{v}}^{\mathbf{1}-\boldsymbol{i}}$ & 100000 & 100000 & 100000 & 100000 & 100000 & 100000 & 100000 & 100000 & 100000 & \\
\hline
\end{tabular}

Table A.8. The objective functions varieties in 1 to 20 th iteration.

\begin{tabular}{ccc}
\hline Iteration & $\begin{array}{c}\text { 1st objective } \\
\text { function }\end{array}$ & $\begin{array}{c}\text { 2nd objective } \\
\text { function }\end{array}$ \\
\hline 1 & 6884310000000 & 7132517000 \\
2 & 5587410000 & 7446646000 \\
3 & 3527926000 & 7760767000 \\
4 & 3508580000 & 8059677000 \\
5 & 3518091000 & 8388973000 \\
6 & 3481251000 & 8697541000 \\
7 & 3466227000 & 9017283000 \\
8 & 3481264000 & 9298305000 \\
9 & 3434906000 & 9588989000 \\
10 & 3502584000 & 9832221000 \\
11 & 3466119000 & 10011000000 \\
12 & 3466282000 & 10587900000 \\
13 & 3434782000 & 10602600000 \\
14 & 3434816000 & 10827200000 \\
15 & 3450619000 & 11408000000 \\
16 & 3434762000 & 11773100000 \\
17 & 3434602000 & 12158600000 \\
18 & 3434581000 & 12175600000 \\
19 & 3434646000 & 12645700000 \\
20 & 3434609000 & 12548800000 \\
\hline
\end{tabular}

\section{Biographies}

Mohammad Mohammadpour Omran was born in 1971 in Iran. He is an Assistant Professor of Industrial Engineering at Iran University of Science and Technology. He received his PhD from Iran University of Science and Technology. His researches are concentrated on operation research, logistics, information systems, and system analysis and quality control.

Rouzbeh Ghousi is an Assistant Professor of Industrial Engineering at Iran University of Science and Technology. He received his $\mathrm{PhD}$ from Iran University of Science and Technology in 2013. His researches are concentrated on safety and healthcare engineering, human reliability, sustainable supply chain management, and data science.

Ahmad Taherkhani Kadkhodaei was born in 1990 in Iran. He received his BS degree in Industrial Engineering and MS degree in Socio-Economic Systems Engineering from Sharif University of Technology. He went to Iran University of Science and Technology as a PhD Candidate in Industrial Engineering from 2015. His researches are concentrated on logistics, especially port-related logistics. 